the perils one encounters in carrying out this technic. According to the author the only safe form of treatment is to place the child as early as possible in a well-made plaster apparatus.

\section{A New Treatment of Whooping Cough.}

A French physician, Dr. de Lamalleree, has been using in the treatment of whooping cough the inhalation of formic acid vapors. All that is required is to burn a pastille of formol on an alcohol lamp every hour. In one to three days the vomiting stops, as well as the fits of coughing. The latter are reduced to two or three in the twenty-four hours. Out of 22 cases Dr. de Lamalleree has had two failures, four tardy results, and 18 complete cures in eight days, the convalescence being included in this period. The treatrnent should, however, be applied in the first eight days, and the patient should be kept in the same room during the whole treatment.

\section{Action for Malpractice Non-Suited.}

A well-known surgeon of Amiens has just been prosecuted for malpractice by the parents of a roung woman on whom he operated two years ago. The parents accused the doctor of having left a compress in the abdomen after having performed laparotomy and pretended that the death of the patient, which took place eleven months afterward, was due to this error in the treatment. No clear proof of this conld be furnished by the parents of the young woman, and they were condemned to pay 1000 franes damages.

\section{Gorrespondence.}

\section{Voluntary National Examining Board.}

Wireflensburi, Ohio, May 12, 1902.

T'o the Editor:--The proposed organization of a national medical examining board as outlined by TIIE JockNaL, January 11. page 108, and adrocated in the last number by Dr. W. L. Rodman, Philadelphia, is a move in the right direction, and to my mind oflers the best practical pian yet suggested for overcoming the abuses which the best elcments of the profession would gladly see abolisher.

With regard to the compensation of the proposed board, about which there seem to be divergent views, I wish to inquire why it might not be feasible to obtain recognition from the trustees of the great Carnegie Institution whose objects, in addition to the promotion of research, are declared to be "to encourage the application of knowledge to the improvement of mankind; to conduct, endow and assist investigation in any department of scientific literature or art, and to this end to ro-operate with governments, universities, colleges, technical sehools, learned societies and inaividuals."

Is not the avowed scope of this institution as here set forth by the trustees, as well as in the proclamation of its distinguished founder, sufficiently broad to admit of entering into legitimate relations in harmony witl: its declared purposes, with such a board as it is now in contemplation to create? Is there any other use to which the immense resources of the institution could be applied that would so stimulate the advancement of practical science, and indirectly promote original research, as an afhiliation ani co-operation with a board especially designed to uplift the qualifications of the most learned of the professions: Would not the board itself derive additional consideration and authority by reason of its con. nection with this unique institution-thus insuring permaneney, independent action and universal recognition, commen surate with its own high character and its distinguished association?

In this event would the board need to limit its action to the bestowal of diplomas of one grade only? Might it not issue certificates of different grades-according to qualificationsjust as the licensing board in England issues the diploma of M.R.C.S. and also the higher diploma of F.R.C.S.? In this way the advantages of a national certificate could be secured by a much larger number of physicians, and need not be confined to the young men of the future who, as Dr. Rodman says, are fresh from the colleges and ambitious. Would not the hope of winning the highest distinctions in the power of the board to confer stimulate numbers to engage in the original research who otherwise would have small incentives to lead them on?

JAMES L. TAYioR.
Derroit, Mich., May 12, 1902.

To the Editor:-I again endorse the idea of a voluntary national examining board. The establishment of such a board' and the movement toward interstaie reciprocity can go very well in hand, and will probably do so for some time to come.

It is to be hoped that all those who will participate in the meeting of the American Medical Association at Saratogaespecially those who will attend in an official capacity-will study the subjects and become familiar with the various sides of the questions.

Some information may be furnished by the confederation of members of Reciprocating State Medical Examining and Licensing Boards, a meeting of which, as I understand, will take place in Chicago, May 20. Very truly yours.

Emil Amberg, M.D.

\section{Chloroform and Gaslight Again.}

Cincago, April 30, 1902.

T'o the litor:-A few days ago a druggist handed me a bottle marked "Squibb's Chloroform" and said that it had been returned to him by a physician, with the statement that it contained so much chlorin that it could not be used for anesthetic purposes. The druggist made inquiry and found that it had been used at night in the presence of an open gaslight. The druggist wished to know whether it contained chlorin or any other injurious impurity. On making the appropriate tests it was found to conform to the pharmacopeial requirements, containing no free chlorin, no acid or other impurity. I then used some of it to anesthetize a patient for an operation lasting 40 minutes and its effects were all that could be desired of chloroform.

This is witten to call attention again to the irritating gas which is formed when the vapor of chloroform comes in contact with a light or a fire. Chloroform is not readily combustible, yet it will burn when the conditions are favorable. The products of this combustion are free chlorin and some very irritating compounds of chlorin, and deaths have been caused by inhaling the mixture so produced at operations where chloroform has been used too freely and without any precautions. All discomfort and danger may be avoided by hanging a towel below the gaslight and keeping the towel moistened with ammonia water throughout the operation. There is no occasion to fill the room with the fumes of ammonia, the amount necessary is small and it is seldom that the operator or his assistants detect its presence. There is little occasion to question the purity of the chloroform and ether at present in the market, and the frequent complaints about impurities in the anesthetics is usually due to ignorance of some such facts as set forth in this communication. Yours truly,

D. H. Galloway

\section{State Boards of Registration.}

In Texas, next week, the State Board of Medical Examiners expect to be very busy, as 100 candidates are expected.

The New Jersey Board of Medical Examiners has exam. ined 87 applicants for medical licenses in the past year; of these, 63 obtained licenses and 24 were refused.

The California Board has had a Chinese doctor arrested for practicing without a license. He has done a large business, among both his own countrymen and white persons.

More Study in Illinois medical schools is proposed by the looard in this state. At the session April 29, in Chicago, a committee proposed the extension of the time required for medical study to eight months in each of four years.

The Pennsylvania Medical Examining Board met in Harrisburg April 1. In organizing, Dr. Henry Beates, Jr.. Phi'a. delphia, was made president, and Dr. H. S. McConnell, New Brighton, secretary. The next examination will be held June 25-28, simultaneously in Pittsburg, at the Central High School, and in Philadelphia, in Industrial Hall.

The Tennessee Medical Examiners held simultaneous ex. aminations at Nashville, Memphis and Knoxville, April 1 and 2 . The number of questions was 64 , on 8 subjects, 60 per cent. 